\title{
Bir Üniversite Hastanesinde Çalışan Hemşirelerde Latekse Bağlı Alerjik Yakınmaların Anket Yöntemi ile Değerlendirilmesi
}

\author{
Investigation of Latex-related Allergic Symptoms \\ on Nurses Working in a University Hospital
}

\author{
Ayşe COŞKUN BEYAN, Arif Hikmet ÇIMRIN, \\ Hande Damla SAVURAN, Ahmet Bahadır TUNCER, Seçilnaz ÜNLÜ, Hakan AYDEMiR
}

\begin{abstract}
ÖZET
Sağlık çalışanlarında lateks malzemelerin kullanımına bağlı ekzama, kontakt ürtiker, rinit, konjonktivit, astım ve anafilaksi gibi durumlar gelişebilmektedir. Hemşireler lateks alerjisi açısından en riskli grubu oluşturmaktadır. Bu çalışma bir üniversite hastanesinde lateks maruziyeti açısından riskli yerlerde çalışan hemşirelerde lateks alerjisine bağlı yakınmaların değerlendirilmesini amaçlamaktadır. Hastane işyeri sağlık ve güvenlik birimi (İSGB) risk değerlendirmesine göre lateks maruz kalımı açısından en riskli kabul edilen dört bölümde, araștırıcılar tarafından oluşturulan anket ile değerlendirme yapıldı. Toplam 63 çalışana (\%85) ulaşıldı. Çalışanların ortalama yaşı 33,1 $\pm 5,7$ yıl idi, \%90,5 'i kadındı. En sık alerjik yakınma çalışanların \%41,3'ünde görülen dermal yakınmalardı.. Çalışanlardan işyerinde kullandıkları malzemeler içinde lateks alerjisi açısından riskli maddeleri sıralamaları \%73 hemşire tarafından ilk sırada pudralı eldiven belirtildi. Çalışanlarda latekse bağlı olduğunu düşündüğümüz yakınmaların yüksek olduğu görülmüştür. Anket ile değerlendirme tarama testi olarak kullanılan ucuz ve basit testlerdir. Lateksin çalışma ortamından kaldırılması ve bu çalışanların izlemi alerjik yakınma ve hastalıklarla mücadele etmek için önemlidir.
\end{abstract}

Anahtar Kelimeler: Lateks, Alerji, Sağlık Çalışanı

\section{ABSTRACT}

The use of latex produtcs by health care workers can lead to multiple symptoms: eczema, contact urticaria, rhinitis, conjunctivitis, asthma, and anaphylaxis. Nurses are the most risky group. The purpose of this study was to deatermine prevalence of latex allergy among murses working in risky places in terms of latex exposure in an university hospital. According to the risk assessment of the employee health and safety unit, the four department considered as the most risky for latex exposure were evaluated by the questionnaire prepared by the researchers. A total of 63 workers were evalueted. Information on sociodemoghrapic datas and complaints were collected through a questionnaire. Mean age of the patients was $33,1 \pm 5,7$ years, and $90.5 \%$ was male. The most common allergic complaint of latex-induced dermal complaints is $41.3 \%$ of employees. Nurses stated powdered gloves as the most risky material for latex allergy. It was seen that the complaints that we thought were latex related to the employees were high. Questionnaire evaluation is an easy and simple test that should be used as a screening test. Removal of latex from the working environment and monitoring of these workers is important to eliminate allergic complaints and diseases.

Keywords: Latex, Allergy, Healthcare Workers

Uzm. Dr. Ayşe COŞKUN BEYAN - Dokuz Eylül Üniversitesi, İş ve Meslek Hastalıkları Bilim Dalı, İzmir, Türkiye Ayşe COŞKUN BEYAN (MD) - Dokuz Eylül University, Department of Occupational Diseases, Izmir, Turkey ORCID ID: 0000-0002-3731-2978 dr.aysecoskun@hotmail.com

Prof.Dr. Arif Hikmet ÇIMRIN - Dokuz Eylül Üniversitesi, İş ve Meslek Hastalıkları Bilim Dalı, İzmir, Türkiye

Prof. Arif Hikmet ÇIMRIN (MD) - Dokuz Eylül University, Department of Occupational Diseases, İzmir, Turkey ORCID ID: 0000-0001-8578-2360_cimrin@deu.edu.tr

Hande Damla SAVURAN, Ahmet Bahadır TUNCER, Seçilnaz ÜNLÜ, Hakan AYDEMiR - Dokuz Eylül Üniversitesi, Tıp Fakültesi Dönem 6 Öğrencileri Hande Damla SAVURAN, Ahmet Bahadır TUNCER, Seçilnaz ÜNLÜ, Hakan AYDEMiR - Dokuz Eylul University, Faculty of Medicine $3^{\text {rd }}$ Grade Students ORCID ID: 0000-0003-0960-3660, 0000-0002-7074-3227, 0000-0001-8707-2047, 0000-0002-3423-0627 


\section{YÖNTEM}

\section{GİRIŞ̧}

Doğal lateks, Hevea Brasiliensis olarak bilinen tropikal kauçuk ağacının özsuyundan elde edilir. Her yıl yaklaşık 12 milyon ton lateks üretildiği ve çok sayıda malzemede kullanıldığı bilinmektedir. Sağlık alanında ilk defa 1851 yılında kullanılmaya başlanmıştır. Eldiven başta olmak üzere 40,000 çeşit medikal ürünün hammaddesini oluşturmaktadır [1].

Günlük hayatta da pek çok malzemenin yapısında bulunması ve çok erken yaştan itibaren maruz kalımın başlaması latekse bağlı gelişebilecek alerjik yakınmalar için risk olarak tanımlanmıştır. Lateks alerjisinin genel populasyonda \% 5 civarında olduğu tahmin edilmektedir [2]. Ancak lateks alerjisi için asıl üzerinde durulan konu normal popülasyondan daha sık temas etmek zorunda kalan lateks üretimi çalışanları ve sağlık çalışanlarıdır [3-6]. Sağlık çalışanları arasında en riskli gruplar arasında ise hemşireler bulunmaktadır.[7]. Lateks alerjisi lokal ve yaygın ürtiker, rinit ve astım gibi değişik hedef organlarda anjioödem gibi ağır jeneralize bir tablodan dermatite kadar reaksiyonlara farklı klinik tablolar gösterebilir [8]. Sağlık çalışanlarında lateks alerjisi prevalansı \%5-17 arasında değişen oranlarda bildirilmektedir[9]. En sık görülen duyarlanma çeşidinin kontakt dermatit olduğu bildirilmiştir $[4,10]$.

Bu çalışmada hastanede İSGB birimi tarafından yapılan risk değerlendirmeye göre, lateks maruziyeti açısından en riskli yerler olarak belirlenmiş 4 birimde çalışmakta olan hemşirelerde, yüksek olasılıkla lateks maruz kalımına bağlı gelişmiş alerjik yakınmaların varlığı ve çalışanların lateks alerjisi ile ilgili bilgi düzeylerininin değerlendirilmesi amaçlanmıştır.

\section{A. Örnek Seçimi}

Araştırma tanımlayıcı türdedir. Hastane İSGB risk değerlendirme verileri kullanılarak lateks maruziyeti açısından en riskli yerler seçilmiştir. İSGB risk değerlendirme (RD) yöntemi olarak 5*5 yöntemini kullanmaktadır. Yönteme göre 15 puan ve üzeri yerler yüksek riskli kabul edilmektedir. RD yönteminde maruz kalım sıklığı ve maruz kalım sonuçları sonuçlarına göre 1'den 5'e kadar değerler verilmektedir. 25 puan en riski 1 puan en az riskli yerler demektir. Puan hesaplanırken ayrıca iş hijyeni uygulamalarının etkisi de düzeltici faktör olarak eklenmektedir. Böylelikle risk puanının kontrol önlemleriyle nasıl değiştiği izlenmektedir.

Buna göre en riskli yerler: anestezi ve dahiliye yoğun bakım servisleri, acil servis ve ortopedi servisi olarak belirlenmiştir.

Çalışma Şubat 2018-Mayıs 2018 tarihleri arasında yürütülmüştür. Belirlenen tarihler arasında aktif olarak bu bölümlerde çalışan hemşire sayısı 74 olarak değerlendirilmiş ve örnek seçilmeden tüm hemşirelere ulaşılması planlanmıştır. Toplam 63 (\%85) çalışana ulaşılabilmiştir.

\section{B. Veri Toplama}

Veri toplama aracı olarak araştırıcılar tarafından oluşturulan anket formu Ek 1' de sunulmuştur. Anketin ilk bölümünde demografik veriler, özgeçmiş ve alışkanlıklar, ikinci bölümde iş öyküsü ve çalışma hayatına ilişkin sorular ve iş ile ilişkili hastalığı olup olmadığını düşünme durumu değerlendirilmiştir. Lateks içeren malzemeleri kullanma durumu sorulmuş ve bu malzemelerin lateks alerjisine yol açma olasılıklarını çalışanların öz değerlendirme yapmaları istenmiştir. Son bölümde yakınmaları ve yakınmaların iş ile ilişkini değerlendiren sorular bulunmaktadır. Alerjik yakınmaları değerlendirmek üzere hazırlanan sorular Euro- 
pean Comminity Health Survey (ECRHS) II anketinden yararlanılarak oluşturulmuştur.

ECRHS II 1998-2002 yılları arasında sürdürülmüş bir izlem programıdır. 10 bin üzeri erişkin anket ve SFT ile değerlendirilmiştir. Alerjik yakınmaları (astım, rinit, dermatit) değerlendirmek için kullanılan anketi uzun form ve kısa tarama formu olarak 2 şekilde tasarlanmıştır [11]. Türkçe geçerlilik güvenirliği yapılmamış olsa da Türk Toraks Derneği Astım Tanı ve Tedavi Rehberi'nde kullanılması önerilen bir ankettir [12].

\section{Etik Kurul Onayı}

$\mathrm{Bu}$ araştırma Dokuz Eylül Üniversitesi Tip Fakültesi Dönem 6 öğrenci çalışma modülü (ÖÇM) kapsamında yürütülen bir çalışmadan hazırlanmıştır. Dokuz Eylül Üniversitesi girişimsel olmayan etik kuruldan onay alınmıştır (Sayı:2018/09-04, Tarih: 05.04.2018).

\section{D. İstatistiksel Analiz}

Verilerin Sonuçların istatistiksel olarak değerlendirilmesi SPSS 18,0 istatistik paket programı kullanılarak yapıldı. Çalışmada sürekli değer alan değişkenler ortalama, standart sapma, maksimum minimum değerleri ve yüzde oranları birlikte verildi.

\section{BULGULAR}

Verilen tarihler arasında aktif olarak bu bölümlerde çalışan 74 hemşirenin 63(\%85) 'üne ulaşıldı. Çalışanların ortalama yaşı $33,1 \pm 5,7$, en genç çalışan 23 en yaşlı çalışan 51 yaşında idi. Çalışanların \%65'i evli idi. 28 (\%44,4) çalışan halen sigara içiyordu. Ortalama 4,6 $\pm 6,0$ paket /yıl sigara kullanılmıştı. $18(\% 28,6)$ çalışanda herhangi bir ilaca ya da besine karşı alerji vardı. Lateks ile çapraz reaksiyona yol açabilen kivi, avokado ya da muz alerjisi olan çalışan yoktu. Hayatının herhangi bir döneminde operasyon geçiren $33(\% 52,4)$ çalışan vardı ancak operasyon sırasında ya da sonrasında latekse bağlı alerjik reaksiyon öyküsü olan yoktu. $11(\% 17,5)$ çalışan düzenli olarak ilaç kullanıyordu en sık kullanılan ilaçlar sırasıyla ; inhaler tedavi, HT ve DM nedeniyle kullanılan ilaçlardı. İş ile ilişkili olduğunu düşündükleri herhangi bir hastalığı olup olmadığı sorulduğunda $31(\% 49,2)$ çalışsan evet, 32(\%52,8) çalışan hayır cevabını verdi. Çalışanlara ait veriler tablo 1 'de sunulmuştur.

Olguların çalşstıkları birimlere göre dağılımı sırasıyla 14 $(\% 22,2)$ kişi acil serviste, 13 (\%20,6) kişi ortopedi servisinde, $15(\% 23,8)$ kişi anestezi yoğun bakım servisinde ve 21 $(\% 33,3)$ kişi dâhiliye yoğun bakım servisi idi. Ortalama

Tablo 1: Çalışanların sosyodemografik özellikleri

\begin{tabular}{lrcc}
\hline & & $\mathrm{N}: 63$ & $\%$ \\
\hline Cinsiyet & Kadın & 57 & 90,5 \\
& Erkek & 6 & 9,5 \\
Medeni durum & & & \\
& Evli & 41 & 65,1 \\
& Bekâr & 22 & 34,9 \\
Sigara kullanımı & & & \\
& İçiyor & 28 & 44,4 \\
& Bırakmış & 8 & 12,7 \\
& Hiç ̇̇çmemiş & 27 & 42,9
\end{tabular}

Kronik hastalık

$\begin{array}{rrr}\text { Evet } & 16 & 25,4 \\ \text { Hayır } & 47 & 74,6\end{array}$

Ailede alerjik hastalık olma durumu

$\begin{array}{rrr}\text { Evet } & 49 & 77,8 \\ \text { Hayır } & & \end{array}$

Düzenli ilaç kullanımı

$\begin{array}{rrr}\text { Evet } & 11 & 17,5 \\ \text { Hayır } & 52 & 82,5\end{array}$

Herhangi bir maddeye karşı alerji öyküsünün varlığı

$\begin{array}{ccc}\text { Evet } & 18 & 28,6 \\ \text { Hayır } & 45 & 71,4\end{array}$

Operasyon öyküsü

Evet $33 \quad 52,4$

Hayır $30 \quad 47,6$

İş ile ilişkili hastalığın olduğunu düşünme durumu

Evet $31 \quad 49,2$

Hayır $32 \quad 50,8$ 
Tablo 2: Çalışma hayatına ilişkin veriler

\section{$\mathrm{N}: 63$}

Çalıştı̆ı bölüm

Acil servis $14(\% 22,2)$

Ortopedi servisi $13(\% 20,6)$

Anestezi yoğun bakım servisi $15(\% 23,8)$

Dahili yoğun bakım servisi $21(\% 33,3)$

Toplam çalışma süresi (yıl)

Ortalama \pm SD $\quad 9,9 \pm 5,4$

Min-max 1-25

Son bölümde toplam çalışma süresi

Ortalama \pm SD $\quad 6,3 \pm 5,3$

Min-max 1-20

Haftada çalışılan gün sayısı

Ortalama \pm SD $\quad 3 \pm 0,8$

Min-max 3-7

Günlük çalışma saati

$\begin{array}{rc}\text { Ortalama } \pm S D & 12 \pm 2,7 \\ \text { Min-max } & 3-16\end{array}$

çalışma süresi 9,9 $\pm 5,4$ yıl idi. En kısa çalışma süresi 1 yıl, en uzun 24 yıl idi. Haftada $3 \pm 0,8$ gün çalışıyorlardı. Ortalama günlük çalışma süresi $12 \pm 2,7$ saat idi. En uzun çalışma süresi 16 saatti. Çalışma hayatına ilişkin veriler Tablo 2'de sunulmuştur.

Çalışma ortamında lateks içeren maddeleri kullanım sıklıklarını değerlendirmelerini istediğimizde en sık kullanı- lan maddeler pudralı lateks eldiven ve enjektör $59(\% 93,7)$ olduğu görüldü. . Olgulardan lateks alerjisi yapabilecek ilk 3 tıbbi malzemeyi sıralamaları istendiğinde sırasıla: 46 hemşire (\%73) eldiven, 10 hemşire $(\% 15,8)$ sonda ve 7 hemşire $(\% 11,1)$ enjektörü alerjen olarak değerlendirdi. Sonuçlar Tablo 3' de sunulmuştur.

Çalışanların \%41,3'ü 'cildinde kaşıntı, kızarıklık olduğunu bildirdi. Göz ile ilgili yakınma sıklığı \%28, burun ile ilgili yakınma sıklığı \%19, nefes darlığı ile ilgili yakınma sıklığı \%14,3 idi. Yakınması olan olgular ilgili kliniklere ileri değerlendirme için yönlendirildi. Araştırma sırasında çalışanlara ek tanısal uygulama yapılmadı. Çalışmanın sonuçları İSGB birimi ile de paylaşıldı. Sonuçlar Tablo 4'de sunulmuştur.

\section{TARTIŞMA}

Çalışmamız, lateks maruz kalımı açısından yüksek riskli olan 4 birimde çalışan hemşirelerde yüksek oranda alerjik yakınmalar olduğunu göstermiştir. En sık alerjik yakınmanın çalışanların \%41,3'ünde görülen dermal yakınmalar olduğu bulunmuştur. Ciltle ilgili yakınması olan 26 hemşireden 7'si yakınmalarının iş ile ilişkili olduğunu belirtmiştir. Bulgularımız sağlık çalışanlarında

Tablo 3: Çalışma ortamında kullanılan lateks malzemelerin sıklığının değerlendirilmesi

\begin{tabular}{cccc}
\hline & & $\mathrm{N}: 63(\%)$ & \\
\hline Eldiven & Hiç Kullanmıyorum & Çok Az Kullanıyorum & Çok Fazla Kullanıyorum \\
Katater & - & $4(6,3)$ & $59(93,7)$ \\
Branül & $19(30,2)$ & $9(14,3)$ & $35(55,6)$ \\
Sonda & $4(6,3)$ & $10(15,9)$ & $49(77,8)$ \\
Enjektör & $11(17,5)$ & $23(36,5)$ & $29(46)$ \\
Maske & $1(1,6)$ & $3(4,8)$ & $59(93,7)$ \\
Ambu & $3(4,8)$ & $22(34,9)$ & $37(58,7)$ \\
Turnike & $2(3,2)$ & $27(42,9)$ & $34(54)$ \\
Tansiyon aleti & $9(14,3)$ & $8(12,7)$ & $46(73)$ \\
Endotrakeal tüp & $3(4,8)$ & $8(12,7)$ & $52(82,5)$ \\
\hline
\end{tabular}


Tablo 4: Çalışanların alerjik yakınmalarının anket sonuçları

\begin{tabular}{|c|c|c|c|}
\hline \multicolumn{4}{|c|}{$\mathrm{N}: 63$} \\
\hline & & Hayır (\%) & Evet (\%) \\
\hline Gözlerde kaşınma, kızarıklık, sulanma var mı? & & $45(71,4)$ & $18(28,6)$ \\
\hline Burunda akınt, kaşınt, hapşırma var mı? & & $51(81)$ & $12(19)$ \\
\hline Nefes darlığı, öksürme, hırılt var mı? & & $54(85,7)$ & $9(14,3)$ \\
\hline Ciltte kaşıntı kızarıklık var mı? & & $37(58,7)$ & $26(41,3)$ \\
\hline \multicolumn{4}{|c|}{ Var olan yakınmaların iş ile ilişkisi olduğunu düşünme durumu } \\
\hline & Göz & $13(20,6)$ & $5(0,79)$ \\
\hline & Burun & $7(11,1)$ & $5(0,79)$ \\
\hline & Solunum sistemi & $6(0,09)$ & $3(0,47)$ \\
\hline & Cilt & $19(30,1)$ & $7(11,1)$ \\
\hline
\end{tabular}

latekse bağlı alerjik yakınmaları değerlendiren diğer çalışmalarla uyumludur. Köse ve arkadaşları sağlık çalışanlarında lateks alerji yakınmalarını değerlendirdikleri araştırmalarında 1115 çalışanın \%61 inde lateks kullanımı sonrası dermal yakınmalar olduğunu bulduklarını bildirmişlerdir [13] . Eren ve arkadaşları sağlık çalışanlarında latekse bağlı en sık alerjik yakınmaların ciltte olduğunu belirtmişlerdir [14].

Sarıcaoğlu ve arkadaşları 100 sağlık personelini değerlendirdikleri araştırmalarında 34 çalışanda dermatite ait bulgular saptadıklarını ve en riskli bölgelerden biri olarak araştırmamıza benzer şekilde yoğun bakımları göstermiştir. Araştırmamıza benzer şekilde yine ortalama çalışma yılı 9 yılın üzerinde olduğunu belirtmişlerdir [8] Yüksek moleküler ağırlıklı maddelere maruz kalım sonrası ortaya çıkan alerji tablosunda duyarlaşma dönemi olduğu bilinmektedir. Lin ve arkadaşları lateks duyarlaşması için 2000 saatin (ortalama 2 yıl) kritik olduğunu bildirmişlerdir [6]. Bizim araştırmamızda çalışma yılı <2 yıl olan yalnızca $4(\% 0,06)$ hemşire olması nedeniyle analiz yapılmamıştır. Sarıcaoğlu ve arkadaşları dermatit açısından diğer etkenleri dışlamak için prick ve yama testi yaptıklarını ancak düşük oranda pozitiflik bulduklarını bildirmişlerdir. Lin ve arkadaşları 1253 olgudan $152(\% 12)$ sinde prick testi pozitifliğini bulduklarını belirtmişlerdir. Ancak olguların yarısının her- hangi bir yakınması olmaması nedeniyle duyarlılıklarının farkında olmadıklarını bulduklarını belirtmişlerdir. Ancak anket ile değerlendirdiklerinde lateks eldivene bağlı kontakt dermatit sıklığı \%35 olarak saptamışlardır. Prick testinin tanısal bir test olmadığı yakınma, öykü ve muayeneler ile birleştirilerek kullanılması ve yorumlanması gerektiğini belirtmişlerdir $[6,8]$. Bizim çalışmamamızda prick ve diğer tanısal testler yapılmamıştır. Olgulara yakınmaları ile ilişkili olası sağlık sonuçları ile ilgili bilgi verilmiş ve ilgili kliniklere yönlendirilmiştir.

Alerjik yakınmalar dışında meslekle ilişkili sağlık sorunlarının varlığı sorulmuştur. Çalışanların \%49,2'si iş ile ilgili bir hastalığı olduğunu düşündüğünü belirtmiştir. Bu bulgu alerjik yakınmalar dışında sağlık çalışanlarının kas iskelet sistemi hastalıkları başta olmak üzere pek çok sistemle ilgili sorunları olabileceğini düşündürmüştür.

Çalışmamızda kullandığımız anket ile çalışanların yakınmalarının değerlendirilmesi yöntemi, popülasyon taramaları için ucuz ve kolay olması nedeniyle sıklıkla tarama testleri olarak kullanılmaktadır. Anketin son bölümünde yakınmaların iş ile ilişkisi sorgulanmıştır. Meslek hastalığı ya da iş ile ilişkili hastalık nedensellik değerlendirmesinde yakınmaların iş ile ilişkili olması çok önemli bir bulgudur. Dermatolojik yakınması olan 26 çalışanın 7(\%26,9) si yakınmalarının işyerinde kötüleştiğini belirtmişlerdir. Mev- 
cut bulgu risk değerlendirme sonuçlarıyla birleştirildiğinde yakınmaların latekse atfedilme olasılığını artırmaktadır [15]. Anket ile tarama yönteminin diğer olumlu tarafları da açık uçlu sorular ile kişilerin konu hakkındaki bilgi düzeyleri değerlendirilebilmesidir. Kartal ve arkadaşları sağlık alanı öğrencilerinde lateks malzeme ve alerji türleri hakkında bilgi ve farkındalık düzeyini değerlendirdikleri araştırmalarında öğrencilerin yarıdan fazlasının lateks ve korunma yönetmeleri hakkında bilgi sahibi olduklarını bulduklarını belirtmiştir.. Biz de araştırmamızda latekse bağlı alerji için yüksek riskli maddeleri sıralamalarını istediğimizde \%73 çalışan ilk sırada pudralı eldivenlerinin sorumlu olduğunu düşündüklerini belirtmiştir. Bu önemli bir bulgudur. İş sağlığı alanında koruyucu uygulamaların planlanmasında öncelikle sorunun tespiti ve farkındalığın oluşu birinci basamaktır [16].

Lateks alerjisinin azaltılması çalışmalarında önce etkin bir risk değerlendirme ve latekse bağlı sağlık sorunlarının tespiti için tarama testleri ve çalışanların lateks alerjisi hakkında bilgilendirilmesi önerilmektedir. Ancak iş sağlığının temel yaklaşımı olan mümkünse riskin ortadan tamamen kaldırılması ya da azaltılması yaklaşımı temel yol olarak izlenmelidir [17]. İngiltere İş Sağlığı ve Güvenliği Kurumu lateks kontrol planında lateks yerine nitril ve vinil malzemelerin kullanımı ve çalışanların izlem programı ile düzenli izlemini önermiştir [18] Ancak nitril ve vinil malzeme ile kaplanmış kişisel koruyucu donanımların (eldiven, maske vb) travmalara ve sızdırmaya karşı lateks kaplamaya göre daha dayanıksız olduğu bildirilmektedir. Ayrıca lateks malzemeye göre daha maliyetli ekipmanlardır. Nadir de olsa nitrile karşı da alerjik yakınmalar olduğu bilinmektedir [19].

Latekse farklı bir alternatif olarak neopren malzemeden üretilen eldivenlerde özellikle alerjik yakınması olan çalışanlar için önerilmektedir. Ancak nitril malzemeye benzer şekilde maliyeti latekse göre daha yüksektir. Bu nedenle kullanımı yeterince yaygınlaşamamıştır [19, 20]. Bizim çalışmamamızda olduğu gibi oluşturulacak kısa anketler izlem için en kolay yoldur ve önerilmektedir [18]. Yapılan iyileştirmelerin alerjik yakınma sıklığı ve hastalıkların prevalansında anlamlı iyileşme sağladığı pek çok araştırmada gösterilmiştir. Korumak en ucuz ve insani yoldur [5, 21].

$\mathrm{Bu}$ araştırmada olgular sadece anket ile değerlendirilmiş ve ileri klinik değerlendirme yapılmamış olması bir kısıtlılık olsa da bu veriler oluşturulan izlem programı için kaynak oluşturmuştur.

Sonuç olarak, lateks sağlık çalışanları için alerji riski iyi bilinen bir maddedir. Çalışanların da bu konuda farkındalığının olduğu söylenebilir. Çalışma ortamında riskin ortadan kaldırılması için çalışmalar yapmak tüm çalışanların sağlığının korunması açısından önemlidir.

\section{KAYNAKLAR}

[1] Burkhart, C., Schloemer, J.\&Zirwas, M., (2015) Differentiation of latex allergy from irritant contact dermatitis, Cutis 96(6) 369-71, 401.

[2] Wu, M., McIntosh, J.\&Liu, J., (2016) Current prevalence rate of latex allergy: Why it remains a problem?, Journal of occupational health 58(2) 138144.

[3] Sanguanchaiyakrit, N., Povey, A.\&Vocht, F., (2014) Personal exposure to inhalable dust and the specific latex aero-allergen, Hev b6. 02, in latex glove manufacturing in Thailand, J Annals of occupational hygiene 58(5) 542-550.

[4] Bousquet, J., Flahault, A., Vandenplas, O., Ameille, J., Duron, J., Pecquet, C., Chevrie, K.\&AnnesiMaesano, (2006) Natural rubber latex allergy among health care workers: a systematic review of the evidence, Journal of Allergy Clinical Immunology 118(2) 447-454.

[5] Kelly, K., Wang, M., Klancnik, M.\&Petsonk, E., (2011) Prevention of $\operatorname{IgE}$ sensitization to latex in health care workers after reduction of antigen exposures, Journal of occupational environmental medicine 53(8) 934-940. 
[6] Lin, C., Hung, D., Chen, D., Wu, H., Lan, J.\&Chen, Y., (2008) A hospital-based screening study of latex allergy and latex sensitization among medical workers in Taiwan, J Microbiol Immunol Infect 41(6) 499-506.

[7] Yassin, M., Lierl, M., Fischer, T., O'Brien, K., Cross, J.\&Steinmetz, C., (1994) Latex allergy in hospital employees, J Annals of allergy 72(3) 245-249.

[8] Sarıcaoğlu, H., Toka, S.\&Algan, S., (2013) Sağlık Çalışanlarında Lateks Alerjisi, TÜRKDERM-Deri Hastalıkları ve Frengi Arşivi 47(2) 94-98.

[9] Edlich, R., Hill, L.G., Woodard, C.\&Heather, C., (2003) Latex allergy: A life-threatening epidemic for scientists, healthcare personnel, and their patients, Journal of long-term effects of medical implants 13 (1).

[10] Leung, R., Ho, A., Chan, J., Choy, D.\&Lai, C., (1997) Prevalence of latex allergy in hospital staff in Hong Kong, J Clinical Experimental Allergy 27(2) 167-174.

[11] ECRHS, Screening questionnaire. Erişim tarihi : 01.04.2019, http://www.ecrhs.org/Quests.htm

[12] Türk Toraks Derneği, Türk Toraks Derneği Astım Allerji Çalışma Grubu, Astım Tanı ve Tedavi Rehberi (2016), sy: 2.

[13] Köse, S., Mandiracioğlu, A., Tatar, B., Gül, S.\&Erdem, M., (2014) Prevalence of latex allergy among healthcare workers in Izmir (Turkey), J Cent Eur J Public Health 22(4) 262-5.

[14] Eren, Ö., Bozkurt , B., Karakaya, G.\&Kalyoncu, F., (2005) Sağlık Personelinin Farklı Bir MeslekHastal1ğı: Lateks Allerjisi, Astım Allerji İmmünoloji (3(2)) 68-72.

[15] Berk, M., Önal, B.\&Güven, R., (2011) Meslek Hastalıkları Rehberi, Çalışma ve Sosyal Güvenlik Bakanlığı, Ankara 12 45-47.

[16] Kartal, Ö., Güleç, M., Muşabak, U., Şener, O., Sarı, O.\&Aydoğan, Ü., (2015) Sağlık öğrencilerinin lateks allerjisi yakınmaları ve farkındalıkları, Gulhane Medical Journal 57(4).

[17] IOHA Basic Principles in Occupational Hygiene, Student manual (2010) sy: 13-16.

[18] HSE (2018). Policy on the Prevention and Management of Latex Allergy sy:38-42.

[19] Beşer, A.\&Topçu, S., (2013) Sağlık alanında kişisel koruyucu ekipman kullanımı, Dokuz Eylül Üniversi- tesi Hemşirelik Fakültesi Elektronik Dergisi 6(4).

[20] Ertekin, M., (2017) Kaplamanın Koruyucu Eldivenlerin Performans Özelliklerine Etkisi, Tekstil ve Mühendis 24(107) 172-180.

[21] Turner, S., McNamee, R., Agius, R., Wilkinson, S., Carder, M.\&Stocks, S., (2012) Evaluating intervengations aimed at reducing occupational exposure to latex and rubber glove allergens, J Occup Environ Med 69(12) 925-931. 